\title{
TRANSPORT PROVISION FOR INCREASING MOBILITY OF RURAL DOCTOR IN TYPICAL DISTRICTS OF THE REPUBLIC OF TUVA
}

\author{
Aylana Ondar, Aleksandr Levshin \\ Russian Timiryazev State Agrarian University, Russia \\ ajlana-o@yandex.ru, alev200151@ rambler.ru
}

\begin{abstract}
The article analyzes the problems of organizing the provision of primary medical care for rural areas of the Republic of Tuva. The necessity of using specialized vehicles to increase the mobility of the paramedic and to perform all functions in the standard operating time is substantiated. A mathematical model has been developed to justify the quantitative and brand composition of vehicles for typical regions of the Republic of Tuva. The outflow of the rural population in the regions of the Republic of Tuva led to a set of accumulated problems that impeded the sustainable development of the region. The state graph is constructed on the basis of statistical data on the work of paramedic-midwifery stations. The simulation research of their effectiveness has been carried out using the theory of queuing systems. The simulation of the functioning of the paramedicmidwife station shows that only 31-37\% of applications can be executed in typical areas: Mongun-Taiginsky, Todzhinsky and Tere-Kholsky districts according to the average data of the number of appeals of the rural population for a normative shift in the work of a paramedic in the absence of a vehicle. It takes the paramedic 1.79-2.17 times more the duration of the regulatory shift to satisfy all incoming applications. The applications can be $100 \%$ fulfilled using a car for a rural doctor. The recommendations have been developed to improve the performance of the rural doctor by increasing his mobility. For this, each paramedic -midwife station (further FAP) must have one specialized car that meets the requirements of ecology and geometric cross-country ability in the hard-to-reach typical areas. It is necessary to have a specialized customer service and reserve cars in the system of transport support for medical care.
\end{abstract}

Keywords: car, health, rural areas, medicine, rural doctor.

\section{Introduction}

The study of rural area development problems is a complex and multi-factor socio-economic system. Rural areas are becoming the most important components of the country. A strategic role in ensuring the stability of the state and strengthening food security have determined that rural development is one of the most important problems in the world [1].

To solve such problems, methods of factor analysis are widely used, which make it possible to group the studied objects into generalized groups (clusters) by the totality of attributes. For this purpose, a cluster analysis of 17 districts of the Republic of Tuva was carried out according to 19 independent features characterizing the climatic factors: snow cover, low air temperature, average January temperature, precipitation, area territory, midpoint of the height of the highlands; road conditions: total number of roads, length of roads that do not meet regulatory requirements; infrastructure indicators: number of rural schools, number of schoolchildren, schoolchildren of shepherd families, number of emergency calls, number of FAPs in rural areas, state of the social sphere: number of rural settlements, rural population, number of people who have left rural areas, migration loss of the rural population, population density, number of shepherd camps. The calculations were performed using the Deductor Studio Academic 5.3 software package according to the calculation method of the Kohonen self-organizing map. As a result of calculations using the analytical platform, the regions were grouped into three clusters and three typical regions of each group were distinguished: Mongun-Taiginsky, Todzhinsky, Tere-Kholsky [2].

The aim of the study is to justify the mobility of a rural doctor to provide medical care to the rural population in typical regions of the republic, confirm the effectiveness of using an all-terrain vehicle.

One of the main problems in rural areas is providing affordable, high-quality medical care to the rural population. Weak development of the health system in rural areas negatively affects the health of the population and the demographic situation. The gap between the rural and urban population is explained by the quality of life: availability of medicine, educational systems including additional, cultural and leisure activities and other social services. Rural areas are important demographic factors that indirectly contribute to social balance [3].

As a result, the accumulated problems will lead to a high level of migration of the rural population. The situation in this area of health remains difficult. The life expectancy of the rural 
population of the republic today is 62 years, one of the lowest among the regions of the Russian Federation [4]. The United States rank 1st in average life expectancy [5]. In the states of Utah and Nevada, the average life expectancy is 78.7 and 75.9 years, respectively [6].

Of particular importance in the development of rural areas is the organization of medical care, compliance with the unity of medical care in urban and rural areas. Health of population is one of the main indicators of life. In the Republic of Tuva, $47 \%$ is the rural population [2]. Mainly important is the conservation of the village, as well as rural residents in it. For comfortable life of the rural population, especially in conditions of low density, is the formation of: social infrastructure, labor activities, economic security, household services.

The implementation of a high level of medical services to rural residents: the development of stationary, mobile and remote forms, timely provision of medicines will lead to the achievement of social development of rural areas. A resident of a rural settlement should not feel isolation from the outside world [7].

A shortage of rural doctors is characteristic of many developed countries. The share of district officers in the total number of Russian doctors is only $13 \%$. For comparison: in France there are almost half $48 \%$, in OECD countries on average - a third [8]. In Canada, there are 2.1 medical practitioners per 1000 residents: it is much lower than the OECD average [9].

Also in Greece, the number of medical personnel is not enough to satisfy the current number of requests from the population, up to 5000 doctors will be required, and there are only 600 of them [10]. In Portugal, more than 150,000 people are currently queuing for surveys - despite the fact that the total population of the country is 10.6 million. It is possible that general statistics hide the extent of the problem in poor and rural areas, where the shortage of medical resources is particularly high and access to health services is even more difficult [11].

\section{Materials and methods}

In the Republic of Tuva, there are 144 rural settlements, of which $20.5 \%$ are provided with regular passenger services, $72.5 \%$ are connected to administrative centers through irregular flights operated by private carriers, $7 \%$ of the settlements are difficult to access, transport communication with which is provided by air. The rural areas of the republic are characterized by low density of the rural population, poor road conditions, inaccessibility of settlements, mountainous terrain, and a sufficiently large service radius [12].

The basics of the medical care system in the village are medical and obstetric centers (FAPs). The district paramedic receives the population in the hospital, provides medical assistance on call at home, is engaged in hospitalization of patients in the district center, conducts preventive examinations of children and adults. With the legislative regulation of the working hours of a rural doctor, he has to work not only on weekdays, but also on weekends and holidays.

In rural areas of the republic, when a call is made to the house, the paramedic serves most of the calls by walking. Shepherd parking is sometimes reached by horse. At the moment, in the rural areas of Tuva, in order to hospitalize a patient in a regional hospital, one has to wait for the ambulance to arrive from the district center, which increases the waiting time.

To increase the efficiency of medical services for the rural population and determine the requirements for increasing the mobility of a rural doctor, an analysis was made of the functioning of paramedic-obstetric centers for typical areas. For this purpose, a mathematical model based on the methods of the theory of queuing has been developed. To describe the system, Markov chains are used, the graph of transition probabilities is shown in Fig. 1, the vertices of which indicate possible states of the system, arrows from one vertex to another indicate possible transitions between the states and arrows indicate the probability of such a transition [13].

Taking into account the functions of a rural doctor, the following system conditions are distinguished: $S_{0}$ - no application, appeals to the FAP, work with methodological documentation, medical assistant rest; $S 1$ - admission of patients in a hospital; $S_{2}-$ a call to the house or to the shepherds' parking; $S_{3}-$ transportation of the patient to the district hospital. The functioning of the health subsystem in rural areas is represented by a state graph (Fig. 1). 


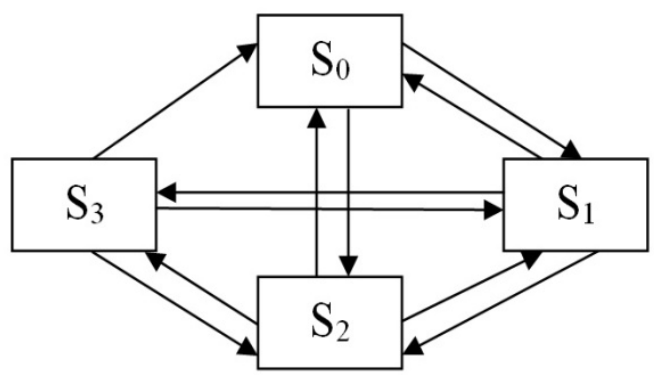

Fig. 1. Graph-state of subsystem

The state probabilities and the value of the transition matrix elements were determined from the statistical data and the components of the balance of the shift time. For the development of time standards the standard time of the rural doctor is used [8].

When traveling to remote inaccessible settlements due to the large distances and the state of the road network, the standard of 15-minute transport accessibility is not fulfilled. Therefore, the model considered the use of various vehicles [9].

The probability of finding an event in each state is found through the norms of the working time of the medical assistant $T_{\text {shift }}$. Shift time components:

$$
T_{\text {shift }}=T_{0}+T_{1}+T_{3}, \min
$$

where $T_{\text {shift }}-$ shift time of the rural medical assistant;

$T_{0}$ - time allotted for the registration of outpatient cards, work with methodological documentation, rest for paramedics;

$T_{1}$ - time of admission of patients in the FAP;

$T_{2}$ - time spent on a call to a house or shepherds' parking;

$T_{3}$ - time spent on transportation to the district hospital.

The standard doctor's daily working hours per day are 7.2 hours or $432 \mathrm{~min}$. [10]. The time allotted for paperwork and rest is found by the formula:

$$
T_{0}=\left(\left(0.35 \cdot t_{\text {serv }}\right) \cdot N_{1}\right)+43.2, \min
$$

where $t_{\text {serv }}$ - regulated time of admission per patient $(18 \mathrm{~min})$;

$N_{1}$ - number of visits to patients in the FAP.

The time for paperwork is $35 \%$ of the time of admission, we take the rest time according to the standard equal to $10 \%$ of the duration of the shift of work of the village doctor. [10]

The duration of admission to the hospital is found by the formula:

$$
T_{1}=\left(\left(N_{1} \cdot t_{s e r v}\right)+\left(N_{s e c} \cdot t_{s e c}\right)\right)+t_{p r 1}, \min
$$

where $N_{1}$ - number of visits to patients in the FAP;

$N_{s e c}$ - number of patients receiving secondary administration;

$t_{s e c}$ - time of patient receiving a second visit $(12 \mathrm{~min})$;

$t_{p r 1}$ - prophylaxis time in FAP.

$T_{2}$ - time spent on a call to a house or a shepherds' parking, determined by the formula:

$$
T_{2}=\left(N_{2} \cdot\left(t_{1}+t_{\text {serv }}\right)+t_{p r 2}\right), \text { min }
$$

where $N_{2}$ - number of calls to the house, to the camp;

$t_{1}$ - time to reach the patient, $\min ; \mathrm{t}_{\mathrm{pr} 2}-$ time for prevention on the road, min.

The time to reach the patient is found using the formula:

$$
t_{1}=\frac{2 \cdot L_{i}}{v_{c p}}, \min
$$

where $L_{i}-$ average distance $(\mathrm{km})$ and $\mathrm{v}$ is the average speed, $\mathrm{km} \cdot \mathrm{h}^{-1}$. 
$T_{3}$ - time spent on transportation to the district hospital according to the following formula:

$$
T_{3}=\left(N_{3} \cdot t_{2}\right)+T_{\text {podg.transp }}, \min
$$

where $N_{3}$ - number of hospitalized in one day;

$t_{2}$ - time of arrival to the patient during hospitalization;

$T_{\text {podg.transp }}$ - preparation time for transportation to the central district hospital.

The functioning of a typical FAP, the activity of the rural doctor is evaluated by the transition probability matrix according to the theory of Markov chains.

$$
P_{i, j}=\left(\begin{array}{cccc}
P_{00} & P_{01} & P_{02} & P_{03} \\
P_{10} & P_{11} & P_{12} & P_{13} \\
P_{20} & P_{21} & P_{22} & P_{23} \\
P_{30} & P_{31} & P_{32} & P_{33}
\end{array}\right),
$$

where $P_{i j}$ - probability of the transition of the system from the $\mathrm{i}$ to the $\mathrm{j}$ state. Matrix elements $P_{i j}$ are non-negative, no more than 1 , and the sum of the elements in any row is 1 .

Knowing the transition matrix, the regularity of the transition of the system from one state to another is determined at regular intervals $t$, which is called a step (7). As the number of steps increases, the matrix (8) tends to a stationary state.

$$
P^{(n)}=P^{0} \cdot P^{n},
$$

where $P^{0}$ - initial matrix;

$P^{n}-$ stationary matrix.

\section{Results and discussion}

For simulation, the following indicators are required: average number of visits in FAP $-N_{1}$, average home calls in countryside and shepherds' parking $-N_{2}$, number of hospitalized in the district hospital $-N_{3}$, number of secondary visits $-N_{\text {sec }}$. Average service radius $L_{i}$, distance from FAP to a district hospital $L$ shown in Table 1 .

In the mathematical model, the values of the transition matrix elements were calculated for different speeds of movement of the rural medical doctor and the time spent is determined $T_{0}, T_{1}, T_{2}$, $T_{3}, T_{\text {shift }}$ at a given service radius. The calculations carried out in Microsoft Excel are shown Table 1.

Initial data for the calculation

Table 1

\begin{tabular}{|c|c|c|c|c|c|c|}
\hline \multirow{2}{*}{ Typical areas } & \multicolumn{4}{|c|}{ Number of applications } & \multicolumn{3}{c|}{ Distance, $\mathbf{k m}$} \\
\cline { 2 - 7 } & $N_{1}$ & $N_{2}$ & $N_{3}$ & $N_{\text {sec }}$ & $L_{i}$ & $L$ \\
\hline Mongun-Taiginsky & 2.50 & 4.50 & 0.250 & 1.25 & 6.0 & 63.0 \\
\hline Todzhinsky & 5.62 & 4.75 & 0.078 & 2.81 & 4.4 & 50.5 \\
\hline Tere-Kholsky & 3.60 & 4.00 & 0.200 & 1.80 & 4.7 & 93.0 \\
\hline
\end{tabular}

Analysis of the initial transition matrix (Fig. 2 a) for Tere-Kholsky district when using a car $\left(30 \mathrm{~km} \cdot \mathrm{h}^{-1}\right)$ shows the likelihood of a doctor working with documents in the FAP (state $\left.S_{0}\right)=0.211$; the likelihood of receiving patients in a hospital (state $S_{1}$ ) $=0.222$; house call or shepherds' parking (state $S_{2}$ ) $=0.391$; and the likelihood of a home call for transporting a patient to a district hospital (state $\left.S_{2}\right)=0.176$.

For the stationary state of the system (Fig. 2 b) the probability $P_{0}=0.453$ increased significantly, the probability $P_{3}$ is almost zero, the probabilities $P_{2}$ and $P_{1}$ have changed insignificantly. The doctor will spend less time on home care. The calculations showed the time $T_{0}, T_{1}, T_{3}$ that does not depend on the speed of movement of the doctor. For district $T_{0}=87.3 \mathrm{~min} ; T_{1}=60 \mathrm{~min} ; T_{3}=65 \mathrm{~min}$, for $T_{0}=108.5 \mathrm{~min} ; T_{1}=134.9 \mathrm{~min} ; T_{3}=16.4 \mathrm{~min} ;$ in district the following results were obtained $T_{0}=91 \mathrm{~min} ; T_{1}=86.4 \mathrm{~min} ; T_{3}=76 \mathrm{~min}$. 


$$
\left(\begin{array}{cccc}
0.211 & 0.374 & 0.415 & 0 \\
0.754 & 0.222 & 0.023 & 0.001 \\
0.591 & 0.016 & 0.391 & 0.001 \\
0.824 & 0 & 0 & 0.176
\end{array}\right)=\left(\begin{array}{cccc}
0.453 & 0.225 & 0.318 & 6.581 \times 10^{-4} \\
0.455 & 0.225 & 0.318 & 6.602 \times 10^{-4} \\
0.454 & 0.224 & 0.317 & 6.589 \times 10^{-4} \\
0.455 & 0.225 & 0.318 & 6.605 \times 10^{-4}
\end{array}\right)
$$

Fig. 2. Initial (left) and stationary (right) transition matrices for Tere-Kholsky district (when using a car)

Dependence of the time of work on calls and the duration of the shift on the speed of movement for typical areas

\begin{tabular}{|c|c|c|c|c|c|c|}
\hline \multirow{2}{*}{ Speed, $\mathbf{~ k m} \cdot \mathbf{h}^{\mathbf{1}}$} & \multicolumn{2}{|c|}{ Mongun-Taiginsky } & \multicolumn{2}{c|}{ Todzhinsky } & \multicolumn{2}{c|}{ Tere-Kholsky } \\
\cline { 2 - 7 } & $T_{2}, \min$ & $T_{\text {shift }}, \min$ & $T_{2}, \min$ & $T_{\text {shift }}, \min$ & $T_{2}, \min$ & $T_{\text {shift }}$ min \\
\hline 5 & 729 & 918.8 & 587.1 & 846.89 & 523.2 & 776.68 \\
\hline 15 & 297 & 509.3 & 252.7 & 512.49 & 222.4 & 475.88 \\
\hline 30 & 189 & 401.3 & 169.1 & 428.89 & 147.2 & 428.89 \\
\hline
\end{tabular}

An analysis of the influence of the speed of movement of a rural doctor shows in Table2 that without using vehicles to perform all functional duties in all typical areas, the doctor will need the time of 1.8-2.1 times the normative shift. With an increase in the speed of movement up to $15 \mathrm{~km} \cdot \mathrm{h}^{-1}$, the time consumption will significantly decrease, but there are more regulatory shifts. The use of motorized means will allow the rural doctor to fulfill all the applications and there will be time for preventive work.

\section{Conclusions}

Thus, providing the rural medical assistant with a car with a minimum speed of $30 \mathrm{~km} \cdot \mathrm{h}^{-1}$, the standard time of $432 \mathrm{~min}$ is fulfilled. Normative working hours of a rural doctor of Mongun-Taiginsky district $T_{\text {shift }}=401.3 \mathrm{~min}$, Tojinsky and Tere-Kholsky $T_{\text {shift }}=401.3 \mathrm{~min}$. In Mongun-Taiginsky district, when leaving for applications in the village, $T_{2}=189 \mathrm{~min}$, in Toginsky $T_{2}=169.1 \mathrm{~min}$, in Tere-Kholsky district $T_{2}=147.2 \mathrm{~min}, 3.5-3.8$ times less than applications executed on foot by a doctor. So, applications in typical areas are currently being implemented only $31-37 \%$. Therefore, for $100 \%$ execution to provide medical services to the rural population typical regions of the Republic of Tuva to perform in order to fulfill the functions of a medical doctor at the standard time, it is necessary to provide the FAP of the village with a specialized vehicle with increased cross-country ability on any terrain, not violating the environment, reliable, easy to operate, with the ability to get to the right place in any weather and road conditions in acceptable time.

\section{References}

[1] Pru B., Bacior S., Dudzinska M. Settlement network concentration as determinant for rural areas development. Engineering for rural development, Jelgava, 24.-26.05.2017, pp. 474-480.

[2] Ondar A.M., Clustering of the districts of the Republic of Tuva according to the level of migration of the rural population. "Collection of the international scientific conference", 2018, December, c. 170-174.

[3] Kaposzta J., Nagy H., Zaien S., Horvath-Csikos G., Solyomfi A.H., Rural development according to regional planning strategies case study (Egypt and Saudi Arabia), Engineering for rural development, Jelgava, 22.-24.05.2019, pp. 1811-1817.

[4] Statistical Yearbook of the Republic of Tuva 2016. [online][11.02.2020] Available at: https://krasstat.gks.ru/folder/45814

[5] Ohsfeldt R.L., Schneider J.E. The Business of Health: The Role of Competition, Markets, and Regulation (Washington: American Enterprise Institute Press, 2006.

[6] Tanner M. A Look at National Health Care Systems Around the World // Policy Analysis. No.613 (March 18, 2008). 
[7] Staroverova G.S., Sustainable rural development monograph/scientific director A.P. Dorogovtsev. 2009, VSTU, Vologda, pp. 79.

[8] Sheiman I., Sazhina S. "The Shortage of Primary Care Physicians - A Global Problem, IQ.HSE Edition.

[9] OECD, "Health at a Glance: OECD Indicators, 2005." https://polit.ru/article/2010/05/31·h ealthcare/

[10] Figueras et al., Health Care Systems in Transition: Greece [online][11.02.2020] Available at: https://polit.ru/article/2010/05/31 $\mathrm{h}^{-1}$ ealthcare/

[11] Oliviera M.D., Bevan G. "Measuring Geographical Inequalities in the Portuguese Health Care System: An Estimation of Hospital Care Needs," Health Policy 66 (March 2003), pp. 277-293.

[12] Ondar A.M., Analysis of transport accessibility of medical care to the population in rural areas of the Republic of Tuva. "International scientific conference of young scientists and specialists dedicated to the 100th anniversary of I. S. Shatilov" 2017, pp. 307-308.

[13] Yezhov I.I., Shurenkov V.M., "Ergodic theorems related to the Markov property of random processes", Probability theory and its application, 21:3 (1976), pp. 635-639.

[14] Shestakov G.S., Baysultanov I.X., Organization of emergency medical care for the population of the rural municipal region. Publishing house "Digital", 2012, Moscow, $232 \mathrm{p}$.

[15] Order No. 290n of 2015, June 2, the Ministry of Health of the Russian Federation. 